\title{
Estudo da isoenzima creatina quinase CKMB sérica em equinos de enduro após exercício físico prolongado
}

Lilian Emy dos Santos MICHIMA $^{1}$

Regina Mieko Sakata

MIRANDOLA ${ }^{1}$

Wilson Roberto

FERNANDES ${ }^{1}$

Correspondência para:

Wilson R Fernandes, Av. Professor Doutor Orlando Marques de Paiva, 87, bl. 12-14, Cidade Universitária, São Paulo-SP, CEP 05508-270.

wilsonrf@usp.br

Recebido para publicação: 28/03/2007 Aprovado para publicação: 07/01/2010

\author{
1 - Departamento de Clínica Veterinária da Faculdade de Medicina \\ Veterinária e Zootecnia da Universidade de São Paulo, São Paulo-SP
}

\section{Resumo}

Com o objetivo de estudar a influência do exercício físico prolongado na indução de lesão miocárdica e na desqualificação de equinos em provas de enduro, colheram-se 87 amostras de sangue de equinos adultos Árabes e mestiços para determinação da concentração sérica da isoenzima $\mathrm{MB}(\mathrm{CKMB})$, da atividade sérica de creatina quinase (CK) e do índice CKMB/CK. Dividiram-se as amostras da seguinte forma: $\mathrm{C}$ (controle, $\mathrm{n}=34)$ : equinos em repouso, no dia anterior à competição; G1 $(n=24)$ : equinos que finalizaram as competições; G2 ( $\mathrm{n}=14)$ : equinos desqualificados durante as competiçóes por causa metabólica e G3 ( $\mathrm{n}=15)$ : equinos desqualificados durante as competiçóes por claudicação. Os valores medianos obtidos de CKMB, para os grupos C, G1, G2 e G3, foram respectivamente 2,25; 2,95; 1,95 e 2,40 ng/mL; para a atividade de CK, os resultados foram 164,2; 1228,0; 840,0 e 581,0 U/L a 30 oC; e para o índice $\mathrm{CKMB} / \mathrm{CK}$, os resultados foram 1,$41 ; 0,21 ; 0,23$ e $0,42 \%$. Houve média correlação positiva entre distância percorrida e CKMB e CK, e negativa entre distância e índice CKMB/CK. O exercício físico de resistência não leva a aumento significante dos valores da isoenzima CKMB, mas sim da atividade sérica da enzima CK, indicando dano à musculatura esquelética. Animais desqualificados por causa metabólica parecem não apresentar envolvimento de lesão miocárdica na causa de desqualificação. Não foi possível verificar a presença de lesão cardíaca induzida pelo exercício em equinos de enduro e sua relação com causas metabólicas de desqualificação a partir da utilização de CKMB como único marcador cardíaco.

\section{Introdução}

Competições de ultra-resistência (por exemplo, provas de ciclismo, triatlo, maratona e ultramaratona) requerem a habilidade de manter uma performance constante de longa duração a uma intensidade de exercício alta, o que pode trazer uma variedade de lesóes ao organismo, como distúrbios eletrolíticos, desidratação, hemoconcentração e disfunção renal. Este mesmo exercício de ultra-enduro pode também provocar lesão na musculatura cardíaca, na maioria das vezes classificada como leve e transitória, como relatado na medicina esportiva humana ${ }^{1,2,3}$.

Dentre as várias ferramentas para a avaliação cardíaca em medicina humana, pode ser utilizada a determinação de marcadores bioquímicos cardíacos, como a isoenzima da creatina quinase $(\mathrm{CKMB}) \mathrm{e}$ as troponinas ${ }^{4,5}$, além de provas de função cardíaca que podem ser realizadas através da 
ecocardiografia ${ }^{6,7,8}$ que, quando associadas e com a análise de atividades enzimáticas como de creatina quinase $(\mathrm{CK})$, trazem informaçóes relevantes que auxiliam ou afastam o diagnóstico de lesão miocárdica causada pelo exercício.

São poucos os estudos em equinos sobre a determinação de marcadores bioquímicos cardíacos, em especial a isoenzima $\mathrm{MB}^{9,10,11,12}$. Argiroudis, Kent e Blackmore ${ }^{9}$ relatam que menos de $1,5 \%$ da atividade total de CK no coração equino corresponde à $\mathrm{CKMB}$, em contraste aos mais de $20 \%$ no coração humano. Assim, seria polêmico o uso desta isoenzima no diagnóstico de lesão miocárdica na espécie equina, pela sua pouca sensibilidade.

O equino é uma espécie atleta por sua natureza, capaz de participar de provas de enduro que podem chegar a distâncias de até $160 \mathrm{~km}$, percorridas em um único dia. Para isso, é necessário que haja um programa de condicionamento físico adequado, para adaptação tanto da musculatura esquelética como também do sistema cardiovascular, além dos outros sistemas orgânicos. Vários fatores podem influenciar a performance do equino durante as provas, entre eles o grau de condicionamento e a intensidade do exercício físico. Assim, animais despreparados ou inexperientes possuem uma tendência maior a não finalizarem o percurso, muitas vezes por motivos de disfunção metabólica.

Ainda não se sabe se o exercício físico de longa duração é capaz de provocar danos ao miocárdio e se estes estão envolvidos nas causas metabólicas de desqualificação em cavalos participantes de competiçóes de enduro. Assim, propôs-se este estudo, com o objetivo de avaliar a influência do exercício de longa duração e média intensidade sobre alguns parâmetros da bioquímica muscular cardíaca, bem como avaliar a possível lesão miocárdica como causa de desqualificaçáo em cavalos de enduro durante as provas, pela determinação da isoenzima CKMB sérica.

\section{Materiais e Métodos}

Colheram-se no total 87 amostras de sangue venoso de equinos adultos hígidos $(10,89 \pm 2,76$ anos), machos e fêmeas, da raça Árabe e seus mestiços, participantes de provas de enduro equestre oficiais, durante os anos de 2002 e 2003. As provas seguiam o regulamento da Confederação Brasileira de Hipismo em vigor na época ${ }^{13}$.

Dividiram-se as amostras da seguinte forma: C (controle), composto de 34 amostras de sangue de equinos em repouso, no dia anterior à competição (pré-exercício); G1 (grupo 1), 24 amostras de sangue de equinos que finalizaram as competiçôes; G2 (grupo 2), 14 amostras de sangue de equinos desqualificados durante as competiçóes por causa metabólica e G3 (grupo 3), 15 amostras de sangue de equinos desqualificados durante as competiçóes por claudicação, sendo estes três últimos grupos compostos de amostras colhidas entre 30 e 90 minutos após o término da prova (pós-exercício).

Procedeu-se a coleta de sangue por punçáo jugular em frascos com sistema de coleta a vácuo, sem anticoagulante, mantendo-se à temperatura ambiente até a formação do coágulo e posteriormente sob refrigeraçáo até o processamento para obtenção do soro, que foi aliquotado e mantido congelado a $-20^{\circ} \mathrm{C}$ até o momento das análises, dentro de um máximo de 168 horas.

Determinou-se a atividade da enzima CKpor método cinético colorimétrico $\left(\mathrm{a} 30^{\circ} \mathrm{C}\right)$ utilizando-se kit comercial (Biosystems). Para a determinação da concentração da isoenzima CKMB (CKMB massa), utilizouse método de imunoquimioluminescência com kit comercial humano (IMMULITE ${ }^{\oplus}$, DPC Medlab) com sensibilidade analítica de $0,42 \mathrm{ng} / \mathrm{mL}$. Obteve-se o cálculo do índice $\mathrm{CKMB} / \mathrm{CK}$ pela razão entre os valores obtidos, apresentando-o em porcentagem.

Procedeu-se a análise estatística dos resultados obtidos com auxílio do pacote estatístico MINITAB ${ }^{\circledR}$ v.13.0. Realizaramse a análise descritiva das variáveis e a 
comparação entre os grupos pela análise de variância e posterior teste de Tukey, em caso de distribuição paramétrica, ou teste de Kruskall-Wallis e posterior teste de MannWhitney, em caso de distribuição assimétrica das variáveis. Avaliou-se a influência do exercício físico sobre a atividade muscular cardíaca por meio de testes de correlação dos postos de Spearman entre as diversas variáveis e a distância percorrida. Para tanto, utilizou-se o nível de significância de 5\% em todos os testes.

\section{Resultados e Discussão}

Os valores medianos da isoenzima CKMB observados para os grupos controle $(2,25 \mathrm{ng} / \mathrm{mL})$, grupo $1(2,95 \mathrm{ng} / \mathrm{mL})$, grupo $2(1,95 \mathrm{ng} / \mathrm{mL})$ e grupo $3(2,40 \mathrm{ng} / \mathrm{mL})$ (Tabela 1 e Figura 1A) são semelhantes aos relatados para potros hígidos com mediana $2,3 \mathrm{ng} / \mathrm{mL}$ e $1^{\circ}$ e $3^{\circ}$ quartis, respectivamente 1,3 e $4,0 \mathrm{ng} / \mathrm{mL}$ observados por Slack et al. ${ }^{12}$, mas maiores que aqueles observados em dois cavalos hígidos $(<0,7 \mathrm{ng} / \mathrm{mL})$ por Cornelisse et $\mathrm{al}^{11}$. Esta disparidade de valores pode ser devida às diferentes metodologias: enquanto os autores citados ${ }^{11}$ utilizaram kit de imunoensaio enzimático (ELISA), empregou-se neste estudo a técnica de imunoquimioluminescência.

Como não foi ainda estabelecido o valor máximo de normalidade para a espécie

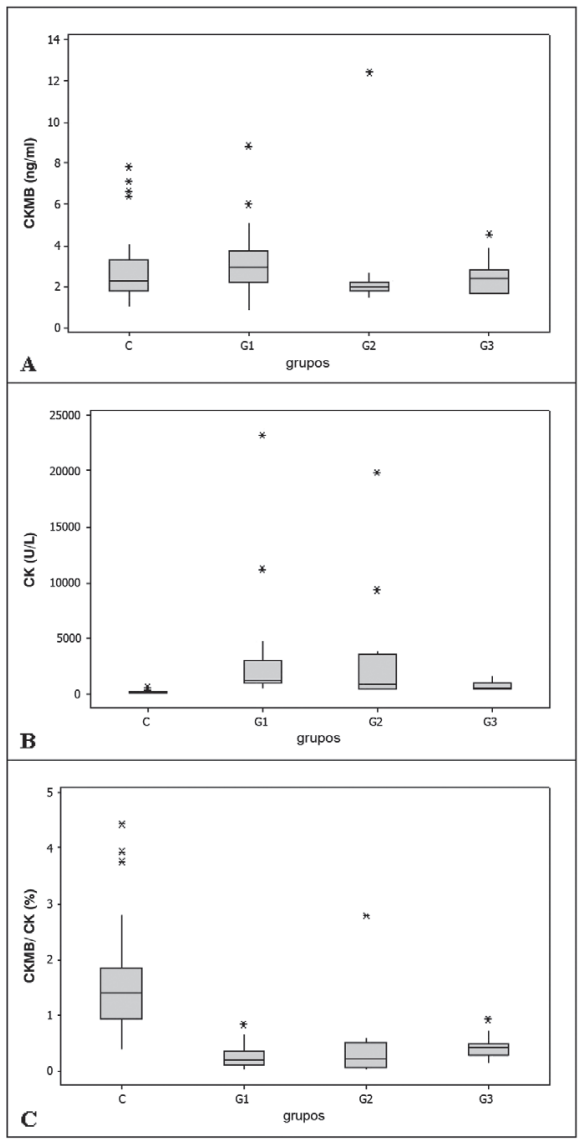

Figura 1 - Boxplots dos valores de CKMB (A) atividade de CK (B) e índice $\mathrm{CKMB} / \mathrm{CK}$ (C) dos equinos participantes de provas de enduro dos grupos C (controle, em repouso no dia anterior à competição) G1 (finalizaram as competições), G2 (desqualificados por causas metabólicas) e G3 (desqualificados por claudicação) - São Paulo - 2009

Tabela 1 - Valores medianos (mínimo-máximo) de CKMB $(\mathrm{ng} / \mathrm{mL})$, atividade de $\mathrm{CK}\left(\mathrm{U} / \mathrm{L}, 30^{\circ} \mathrm{C}\right)$ e índice $\mathrm{CKMB} /$ CK (em porcentagem) dos equinos participantes de provas de enduro dos grupos $\mathrm{C}$ (controle, em repouso no dia anterior à competição), G1 (finalizaram as competições), G2 (desqualificados por causas metabólicas) e G3 (desqualificados por claudicação) - São Paulo - 2006

\begin{tabular}{|c|c|c|c|c|}
\hline Grupo & $N$ & CKMB (ng/mL) & CK (U/L) & CKMB/CK (\%) \\
\hline \multirow{2}{*}{ C } & \multirow{2}{*}{34} & $2,25^{A}$ & $164,2^{\mathrm{A}}$ & $1,41^{A}$ \\
\hline & & $(1,00-7,80)$ & $(111,7-615,1)$ & $(0,39-4,43)$ \\
\hline \multirow{2}{*}{ G1 } & \multirow{2}{*}{24} & $2,95^{\mathrm{A}}$ & $1228,0^{B}$ & $0,21^{\mathrm{B}}$ \\
\hline & & $(0,81-8,80)$ & $(431,0-23281,0)$ & $(0,01-0,84)$ \\
\hline \multirow{2}{*}{ G2 } & \multirow{2}{*}{14} & $1,95^{\mathrm{A}}$ & $840,0^{\mathrm{BC}}$ & $0,23^{\mathrm{BC}}$ \\
\hline & & $(1,40-12,40)$ & $(321,0-19853,0)$ & $(0,01-2,79)$ \\
\hline \multirow{2}{*}{ G3 } & \multirow{2}{*}{15} & $2,40^{A}$ & $581,0^{\mathrm{C}}$ & $0,42^{\mathrm{C}}$ \\
\hline & & $(1,60-4,50)$ & $(282,0-1631,0)$ & $(0,13-0,93)$ \\
\hline
\end{tabular}

Caracteres diferentes indicam diferença estatística significante $(p<0,001$, Kruskall-Wallis) 
equina, utilizando as orientaçóes da European Society of Cardiology e do American College of Cardiology ${ }^{14}$ é possível concluir que os equinos participantes das competiçôes de enduro apresentaram valores de CKMB não excedentes àqueles do $99^{\circ}$ percentil estabelecido para o plasma humano, cujos resultados variavam de 3,9 a 7,9 ug/L. Então, considerou-se positivo para infarto do miocárdio, o resultado cujo valor fosse duas vezes este percentil. Embora possa haver diferenças entre as concentraçóes séricas e plasmáticas e entre as espécies, pelos mesmos procedimentos, obtém-se um valor de $99^{\circ}$ percentil de $7,37 \mathrm{ng} / \mathrm{mL}$ para os equinos em repouso. Somente um animal do grupo 1 e outro do grupo 2 apresentaram valores acima deste, mas não correspondentes ao dobro deste valor $(8,80$ e $12,40 \mathrm{ng} / \mathrm{mL}$, respectivamente).

Náo houve diferença estatística significante nos valores da isoenzima CKMB pós-exercício em relação ao repouso (controle), nem entre os valores dos grupos pós-exercício entre si. Apesar deste fato, é possível notar que os equinos que percorreram maiores distâncias (G1, p<0,001, Tabela 2) tenderam a valores mais elevados desta isoenzima, sendo este comportamento comprovado por apresentar uma média correlação linear positiva de 30,5\% ( $\mathrm{p}=$ 0,03 ) (Figura 2A). Esta observação ocorreu de modo similar em atletas humanos ${ }^{3}$. Esta constataçáo pode indicar que o aumento da carga de trabalho pode levar ao aumento gradual da fadiga muscular e também levar à lesáo miocárdica, de forma e talvez transiente, como sugerido por Cleave et al. ${ }^{1}$ e Neumayr et al. ${ }^{2}$, pois os valores da isoenzima permanecem dentro dos limites de valor basal. Em contrapartida, em atletas

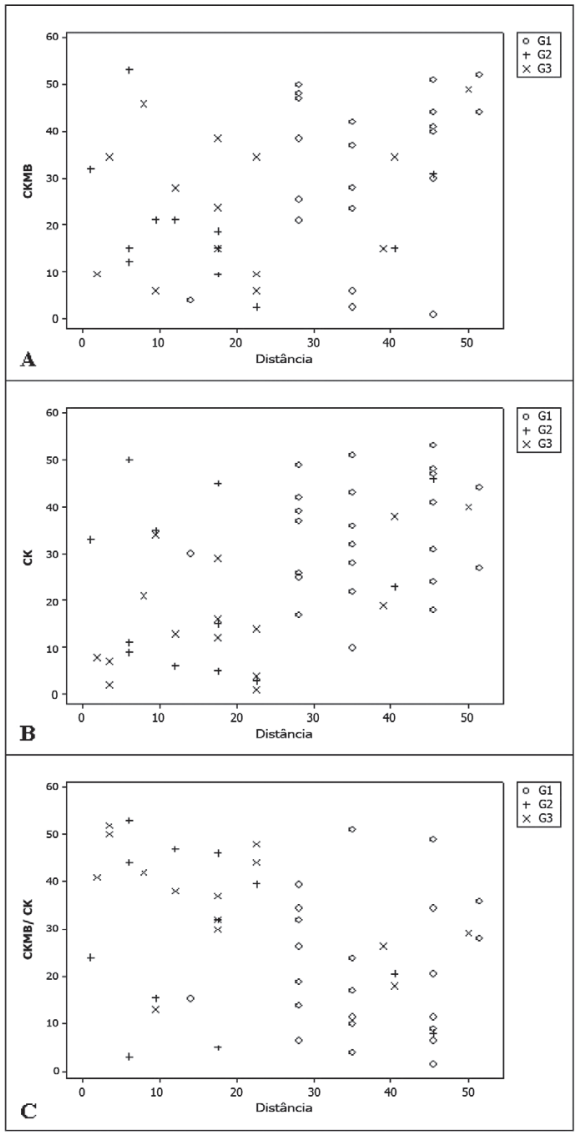

Figura 2 - Representação gráfica da distribuição dos postos de Spearman para CKMB (A) atividade de CK (B), índice CKMB/CK (C) e distância percorrida dos equinos participantes de provas de enduro dos grupos C (controle, em repouso no dia anterior à competição), G1 (finalizaram as competições), G2 (desqualificados por causas metabólicas) e G3 (desqualificados por claudicação) - São Paulo - 2009

Tabela 2 - Valores de média e erro padrão da média da distância percorrida (em km) pelos equinos participantes de provas de enduro dos grupos G1 (finalizaram as competições), G2 (desqualificados por causas metabólicas) e G3 (desqualificados por claudicação) - São Paulo - 2006

\begin{tabular}{cccc}
\hline Grupo & N & Distância $(\mathbf{k m})$ & EP \\
\hline G1 & 24 & $113,88^{\mathrm{A}}$ & 3,81 \\
G2 & 14 & $78,28^{\mathrm{B}}$ & 6,27 \\
G3 & 15 & $83,15^{\mathrm{B}}$ & 6,45 \\
\hline
\end{tabular}

Caracteres diferentes indicam diferença estatística significante $(p<0,001$, ANOVA). N: número amostral; EP: erro padrão da média 
bem treinados, o exercício extenuante não resulta em dano ou disfunção ao coração e as elevaçóes de CKMB são mais prováveis pelo dano ao músculo esquelético, já que os níveis de troponina I cardíaca se mantiveram dentro dos limites na maioria dos indivíduos ${ }^{6,7}$.

Por outro lado, os animais do grupo 2, desqualificados por causas metabólicas, apresentaram valores menores de CKMB, que embora náo significantes foram mais baixos inclusive que o valor de repouso. Não foi encontrada na literatura qualquer explicação para este fato; uma das possibilidades seria que por estes animais possuírem distúrbios metabólicos, também houvesse alguma alteração do clearance da isoenzima. Este distúrbio metabólico, que per se levaria a uma queda de desempenho, poderia ter uma ação de proteção do coração, poupando-o de algum dano por impedir que o equino exercesse alta carga de trabalho cardiovascular à qual não estivesse preparado. Desta forma, mesmo percorrendo distâncias similares ao grupo 3 (equinos desqualificados por claudicação) (Tabela 2), os animais do grupo 2 apresentariam valores menores de CKMB, sugerindo que a causa da desqualificação destes animais seria outra que não cardíaca. Entretanto, a falta de significância estatística impossibilita esta confirmação, quer devido ao próprio comportamento da isoenzima, quer por outras intercorrências, como o número amostral pequeno ou momento de coleta, tornando-se necessário investigar mais aprofundadamente estas questóes interferentes para a melhor interpretação dos resultados da CKMB.

Em relação à atividade da enzima creatina quinase isoladamente, os valores medianos pós-exercício dos grupos 1 (1228,0 $\mathrm{U} / \mathrm{L}), 2$ (840,0 U/L) e 3 (581,0 U/L) diferem significantemente $(\mathrm{p}<0,001)$ do valor de repouso do grupo controle (164,2 U/L) (Tabela 1 e Figura 1B), fato este esperado, como também já relatado em equinos ${ }^{15,16}$ e na medicina esportiva humana ${ }^{2,3}$, já que o exercício físico exige atividade muscular esquelética. De maneira semelhante à isoenzima CKMB, a atividade de CK possui uma média correlação linear positiva ( $47,1 \%$, $\mathrm{p}<0,001$ ) (Figura 2B) com a distância percorrida, ou seja, quanto maior a distância e a carga de trabalho, maior a demanda de trabalho muscular esquelético e por conseguinte, maiores os valores da enzima (Tabelas 1 e 2). Mas isto não indica haver sempre predisposiçáo a miopatias graves nos animais que percorrem maiores distâncias, como sugerido por Schott II et $\mathrm{al}^{16}$. A atividade desta enzima pode ser resultado do aumento do extravasamento das fibras musculares intactas, pelo simples aumento da atividade muscular, sem, portanto haver uma alteração permanente na integridade celular ${ }^{5}$. Como os equinos do grupo 1 finalizaram as competições em boas condições físicas, náo sendo observada qualquer manifestação clínica que indicasse enfermidade, assim como relatado por outros autores ${ }^{15,17}$, o extravasamento explicaria melhor o aumento da atividade enzimática muscular que a mionecrose.

Ao contrário do ocorrido com a isoenzima CKMB e dos resultados observados por Schott II et al. ${ }^{16}$, o grupo 2 apresentou tendência a valores mais elevados de $\mathrm{CK}$ em relação aos animais do grupo 3 , indicando que houve maior participação muscular esquelética no comprometimento metabólico dos animais do segundo grupo, enquanto os animais do grupo 3 teriam principal causa de claudicação outra que náo muscular.

$\mathrm{O}$ índice $\mathrm{CKMB} / \mathrm{CK}$ avalia a proporcionalidade entre a isoenzima $\mathrm{MB}$ em relação à enzima $\mathrm{CK}$, aumentando a especificidade da CKMB, mas diminuindo sua sensibilidade 5 . Índices menores que 6\% em humanos indicam desbalanço entre as isoenzimas MB e MM e consequuentemente dano à musculatura esquelética ${ }^{10}$. Desta forma, o índice é útil na diferenciação entre lesão muscular cardíaca ou esquelética. Houve diminuição dos valores do índice no pós-exercício nos grupos 1 (0,21\%), 2 $(0,23 \%)$ e $3(0,42 \%)$, em relação ao grupo controle em repouso $(1,41 \%)$ (Tabela 1 e Figura $1 \mathrm{C}$ ), fato não relatado por outros pesquisadores (pois o enfoque seria o estudo 
dos atletas humanos que apresentaram valores de índice maior que $6 \%$, indicando dano miocárdico). Intuitivamente pode-se afirmar que houve aumento não proporcional entre a isoenzima $\mathrm{MB}$ e a CK. Desta forma, a partir da sugestáo de Cardinet $\mathrm{III}^{10}$, seria correto dizer que o exercício físico demanda mais da musculatura esquelética que cardíaca em eqüinos.

Deste ponto de vista, para a avaliaçáo de possível lesão miocárdica causada pelo exercício, este índice não seria muito adequado, pois o aumento desproporcional da isoenzima poderia trazer confusão ao diagnóstico, como relatado por diversos autores ${ }^{2,3,6,8}$. Outro fato importante a ser ressaltado é que apesar de estar em maior proporção no tecido cardíaco, a isoenzima $\mathrm{MB}$ também está presente, em menor concentração (cerca de 3\% em humanos), no tecido muscular esquelético ${ }^{18}$, ocorrendo o mesmo na espécie equina, em uma proporção de $0,4 \%{ }^{9}$, explicando o fato da diminuição dos valores do índice $\mathrm{CKMB} /$ CK. Muito provavelmente o valor diagnóstico deste índice para lesão cardíaca tenha maior significado na análise do animal em repouso, quando então fosse excluída a influência do exercício e verificar-se-ia a maior proporção da isoenzima $\mathrm{MB}$ em relação aos valores normais, associada ao seu valor absoluto mais alto.

Entre os três grupos no momento pós-exercício, o menor valor do índice foi observado para aqueles animais que concluíram o percurso das provas e o maior valor para os animais que claudicaram. Estes últimos, por não possuírem comprometimento metabólico e pela carga de exercício ser menor, apresentariam um valor de enzima CK e da sua isoenzima $\mathrm{MB}$ inferior ao do grupo 1 (Tabela 1), o que acarretaria em um índice $\mathrm{CKMB} / \mathrm{CK}$ maior. Já os animais metabolicamente comprometidos, apesar de terem percorrido distâncias similares, por apresentarem aumento da enzima CK em um nível intermediário, resultou em um valor também intermediário em relação aos outros dois grupos, havendo também a influência do menor valor de isoenzima $\mathrm{MB}$ no cálculo do índice.

Observou-se também a presença de média correlação linear entre o índice CKMB/
CK e a distância percorrida, desta vez um coeficiente negativo $(-36,1 \%, \mathrm{p}<0,001)$ (Figura 2C), reforçando a idéia de tendência ao aumento desproporcional da isoenzima $\mathrm{MB}$ em relação à atividade total de $\mathrm{CK}$.

$\mathrm{Na}$ medicina esportiva humana, o diagnóstico de lesão miocárdica é feito principalmente pela determinaçáo dos níveis de troponinas I e T cardíacas, e não pela isoenzima $\mathrm{MB}$, pois esta última, na presença de dano muscular esquelético, perde especificidade, não havendo correlação entre seu aumento e o aumento das troponinas ${ }^{2,3,8}$.

No decorrer deste trabalho, houve dificuldade na inferência sobre a presença ou não de lesão cardíaca, tanto pela pouca sensibilidade apresentada pela isoenzima CKMB no diagnóstico de dano miocárdico, como citado por Argiroudis, Kent e Blackmore9, como por sua baixa especificidade pelos motivos anteriormente citados. Pode-se concluir então que a utilização de CKMB como único marcador cardíaco não traz informações relevantes a respeito da integridade cardíaca sob influência do exercício. Deve-se ressaltar, no entanto, que este estudo foi realizado com um kit comercial que utiliza anticorpos monoclonais murinos para a detecção de CKMB humana, que pode não possuir sensibilidade e especificidade suficientes para a adequada determinação dos níveis da isoenzima equina em questáo. Portanto, seriam necessárias outras pesquisas para a comparação estrutural e a determinação das isoenzimas de creatina quinase entre as diversas espécies.

Outra hipótese a ser levantada seria quanto à hipertrofia cardíaca desenvolvida com o treinamento. É conhecido que o condicionamento físico leva a alteraçóes no organismo, inclusive nas musculaturas esquelética e miocárdica ${ }^{19,20}$. É sabido também que os animais de enduro seguem um programa gradual de treinamento e de participação em provas, para que haja um respeito ao limite de sua capacidade. Assim, somente participam de provas de maiores distâncias aqueles animais que já concluíram um número mínimo de provas mais 
$\operatorname{curtas}^{13}$. Desse modo, são considerados mais experientes e com melhor condicionamento de resistência aqueles animais que participam de competiçóes com distâncias maiores. Não seria errada então a suposição de que estes animais possuam um coração mais adaptado a estas condiçóes e, portanto, um coração mais hipertrofiado. Assim, os valores correspondentes da isoenzima $\mathrm{CKMB}$ seriam um reflexo do tamanho cardíaco destes animais, refletindo desta maneira também o seu estado de condicionamento físico e aumentando proporcionalmente sua concentração sérica com o exercício. Mas para que seja possível tal conclusão, são necessários estudos complementares, incluindo a utilização de outros métodos de avaliação cardíaca, como a ecocardiografia e a eletrocardiografia, além do acompanhamento do período de treinamento e do desempenho nas provas.

\section{Conclusões}

Conclui-se, com este trabalho, que o exercício físico de longa duraçáo e média intensidade não leva a aumento significante dos valores da isoenzima $\mathrm{CKMB}$, mas sim da atividade sérica da enzima CK. Animais desqualificados por causa metabólica podem apresentar lesão muscular esquelética, mas parece não apresentar envolvimento de lesão miocárdica na causa de desqualificação.

Por causa da dificuldade encontrada em se determinar presença de lesão miocárdica induzida pelo exercício em equinos de enduro somente a partir da isoenzima $\mathrm{MB}$, talvez a interpretação dos resultados seja mais bem feita quando analisada em conjunto com outras variáveis, como a troponina I cardíaca e as variáveis de função cardíaca dadas pela ecocardiografia. Assim, são necessários mais estudos com aprofundamento na avaliação cardíaca para que se possa inferir sobre o diagnóstico das alteraçóes cardíacas e diferenciar as patológicas daquelas fisiológicas devido ao condicionamento físico.

\section{Agradecimento}

Os autores agradecem à Sra. Vanda Gutierrez, do Serviço de Laboratório Clínico do Hospital Universitário da Universidade de São Paulo, pelas dosagens das amostras.

\title{
Study of serum creatine kinase isoenzyme CKMB in endurance horses after prolonged physical exercise
}

\begin{abstract}
With the purpose of studying the influence of prolonged phyisical exercise causing myocardial lesion and disqualifying horses in endurance competitions, 87 blood samples were collected from adult Arabian and crossbred horses, to determine the serum concentration of the isoenzyme $\mathrm{MB}(\mathrm{CKMB})$, the serum activity of creatine kinase $(\mathrm{CK})$, and the $\mathrm{CKMB} / \mathrm{CK}$ index. Samples were divided as follows: $\mathrm{C}$ (control, $\mathrm{n}=34)$ : horses at rest, one day before competition; G1 $(\mathrm{n}=24)$ : horses which finished competitions; G2 ( $\mathrm{n}=14)$ : horses disqualified during competitions by metabolic causes, and G3 $(n=15)$ : horses disqualified during competitions after lameness was diagnosed. Median values obtained for CKMB, for groups C, G1, G2, and G3, were, respectively, $2.25 ; 2.95 ; 1.95$, and $2.40 \mathrm{ng} / \mathrm{mL}$; for CK activity, the results were $164.2 ; 1228.0 ; 840.0$, and 581.0 in $\mathrm{U} / \mathrm{L}$ at $30^{\circ} \mathrm{C}$; and for $\mathrm{CKMB} / \mathrm{CK}$ index, the results were $1.41 ; 0.21 ; 0.23$, and $0.42 \%$. There was mean positive correlation between distance and $\mathrm{CKMB}$ and $\mathrm{CK}$, and negative correlation between distance and $\mathrm{CKMB} / \mathrm{CK}$ index. It was concluded that endurance exercise does not cause significant increases in CKMB
\end{abstract}

Keywords:

Horse. Endurance. Creatine kinase. 
values, but in CK serum activity, indicating skeletal muscle injury. Horses disqualified by metabolic causes seem not to present myocardial injury involved in the cause of disqualification. It was not possible to verify the presence of exercise-induced cardiac injury in endurance horses and its relationship with metabolic causes of disqualification only by the utilization of CKMB as the only cardiac marker.

\section{Referências}

1 CLEAVE, P.; BOSWELL, T. D.; SPEEDY, D. B.; BOSWELL, D. R. Plasma cardiac troponin concentrations after extreme exercise. Clinical Chemistry, v. 47, n. 3, p. $608-610,2001$

2 NEUMAYR, G.; GAENZER, H.; PFISTER, R.; STURM, W.; SCHWARZACHER, S. P.; EIBI, G.; MITTERBAUER, G.; HOERTNAGL, H. Plasma levels of cardiac troponin I after prolonged strenuous endurance exercise. The American Journal of Cardiology, v. 87, n. 3, p. 369-371, 2001.

3 WHYTE, G. P.; GEORGE, K.; SHARMA, S.; LUMLEY, S.; GATER, P.; PRASAD, K.; MCKENNA, W. J. Cardiac fatigue following prolonged endurance exercise of differing distances. Medicine Science and Sports Exercise, v. 32, n. 6, p. 1067-1072, 2000.

4 CHU, W. W.; DIETER, R. S.; STONE, C. K. A review of clinically relevant cardiac biochemical markers. Winsconsin Medical Journal, v. 101, n. 3, p. 40-47, 2002.

5 MAIR, J. Tissue release of cardiac markers: from physiology to clinical applications. Clinical Chemistry and Laboratory Medicine, v. 37, n. 11/12, p. 1077-1084, 1999.

6 DÁVILA-ROMÁN, V. G.; GUEST, T. M.; TUTEUR, P. G.; ROWE, W. J.; LADENSON, J. H.; JAFFE, A. S. Transient right but not left ventricular dysfunction after strenuous exercise at high altitude. Journal of the American College of Cardiology, v. 30, n. 2, p. 468-473, 1997.

7 LA GERCHE, A.; BOYLE, A.; WILSON, A. M. No evidence of sustained myocardial injury following an Ironman distance triathlon. International Journal of Sports Medicine, v. 25, n. 1, p. 45-49, 2004.

8 RIFAI, N.; DOUGLAS, P. S.; O'TOOLE, M.; RIMM, E.; GINSBURG, S. Cardiac troponin T and I, electrocardiographic wall motion analyses and ejection fractions in athletes participating in the Hawaii Ironman triathlon. The American Journal of Cardiology, v. 83, n. 3, p. 1085-1089, 1999.

9 ARGIROUDIS, S. A.; KENT, J. E.; BLACKMORE, D. J. Observations on isoenzymes of creatine kinase in equine serum and tissues. Equine Veterinary Journal, v. 14 , n. 4 , p. $317-321,1982$.

10 CARDINET III, G. H. Clinical biochemistry of domestic animals. 4. ed. San Diego: Academic Press, 1989. cap. 17, p. 462-495.

11 CORNELISSE, C. J.; SCHOTT II, H. C.; OLIVIER, N. B.; MULLANEY, T. P.; KOLLER, A.; WILSON, D. V.; DERKSEN, F. I. Concentration of cardiac troponin I in a horse with a ruptured aortic regurgitation jet lesion and ventricular tachycardia. Journal of the American Veterinary Medical Association, v. 217, n. 2, p. 231-235, 2000.

12 SLACK, J. A.; MCGUIRK, S. M.; ERB, H. N.; LIEN, L.; COOMBS, D.; SEMRAD, S. D.; RISEBERG, A.; MARQUES, F.; DARIEN, B.; FALLON, L.; BURNS, P.; MURAKAMI, M. A.; APPLE, F. S.; SIMON, F. Biochemical markers of cardiac injury in normal, surviving septic, or nonsurviving septic neonatal foals. Journal of Veterinary Internal Medicine, v. 19, n. 4, p. 577-580, 2005.

13 CONFEDERAÇÃO BRASILEIRA DE HIPISMO $(\mathrm{CBH})$. Regulamento de enduro eqüestre: Modalidade velocidade livre. Rio de Janeiro: Confederação Brasileira de Hipismo, 2000. 64 p.

14 APPLE, F. S.; QUIST, H. E.; DOYLE, P. J.; OTTO, A. P.; MURAKAMI, M. M. Plasma 99th percentile reference limits for cardiac troponin and creatine kinase $M B$ mass for use with European Society of Cardiology/American College of Cardiology Consensus recommendations. Clinical Chemistry, v. 49, n. 8. p. 1331-1336, 2003.

15 ANDREWS, F. M.; GEISER, D. R.; WHITE, S. L.; WILLIAMSON, L. H.; MAYKUTH, P. L.; GREEN, E. M. Haematological and biochemical changes in horses competing in a 3 Star horse trial and 3-day-event. Equine Veterinary Journal, v. 27, p. 57-63, 1995. Supplement, 20.

16 SCHOTT II, H. C.; MARLIN, D. J.; GEOR, R. J.; HOLBROOK, T. C.; DEATON, C. M.; VINCENT, T.; DACRE, K.; SCHROTER, R. C.; JOSE-CUNILLERAS, E.; CORNELISSE, C. J. Changes in selected physiological and laboratory measurements in elite horses competing in a $160 \mathrm{~km}$ endurance ride. Equine Veterinary Journal, v. 36, p. 37-42, 2006. Supplement, 36.

17 ROSE, R. J.; HODGSON, D. R. Hematology and biochemistry. In: ROSE, R. J.; HODGSON, D. R. The athletic horse: principles and practice of equine sports medicine. Philadelphia: W. B. Saunders, 1994. p. 72.

18 URDAL, P.; URDAL, K.; STROMME, J. H. Cytoplasmic creatine kinase isoenzymes quantitated in tissue specimens obtained at surgery. Clinical Chemistry, v. 29, n. 2, p. 310-313, 1983.

19 EVANS, D. L. The cardiovascular system: anatomy, physiology and adaptations to exercise and training. In: ROSE, R. J.; HODGSON, D. R. The athletic horse: principles and practice of equine sports medicine. Philadelphia: W. B. Saunders, 1994. p. 129-1144.

20 SNOW, D. H.; VALBERG, S. J. Muscle anatomy, physiology, and adaptations to exercise and training. In: ROSE, R. J.; HODGSON, D. R. The athletic horse: principles and practice of equine sports medicine. Philadelphia: W. B. Saunders, 1994. p. 145-108. 